\title{
Petrographic features of oceanic peridotites as reflected by their magnetic characteristics
}

\author{
B. A. Bazylev ${ }^{1}$, K. V. Popov ${ }^{2}$, and V. P. Shcherbakov ${ }^{3}$ \\ ${ }^{1}$ Vernadsky Institute of Geochemistry and Analytical Chemistry, Russian Academy of Sciences \\ ${ }^{2}$ Shirshov Institute of Oceanology, Russian Academy of Sciences \\ ${ }^{3}$ Borok Geophysical Observatory, Schmidt United Institute of Physics of the Earth
}

\begin{abstract}
Petrographic and petromagnetic studies of a representative collection of peridotites from various localities on the Mid-Atlantic Ridge have been carried out. It is shown that secondary magnetization of peridotites comes into being usually prior to the onset of serpentinization, in the course of the preceding medium-temperature metamorphic recrystallization of the rocks. The formative conditions of magnetite in peridotites can be inferred from its integrated grain size, quantified from petromagnetic characteristics. Grain size of magnetite that is formed during serpentinization of oceanic peridotites averages $3-4 \mu \mathrm{m}$. Increased mean grain size of magnetite $(20 \mu \mathrm{m}$ or more) is suggestive of its having crystallized in the course of medium-temperature metamorphism of peridotites. Based on our own and published data, an increased mean grain size of the magnetic phase is characteristic of most oceanic peridotites, which provides a further proof of extensive development of medium-temperature metamorphic recrystallization of these rocks both within transform faults and on rift valley slopes. The obtained data afford the conclusion that the thickness of the magnetic layer of the MOR lithosphere ranges from 6 to $15 \mathrm{~km}$, its lower limit being set by the $580^{\circ} \mathrm{C}$ isotherm, corresponding to the Curie point for magnetite.
\end{abstract}

\section{Introduction}

Magnetization of the rocks that compose oceanic lithosphere is pronounced in the broad development of the wellknown magnetic lineations both within mid-ocean ridges and on their flanks, as well as, to some extent, on abyssal plains. At first, the presence of these anomalies was attributed to basalts erupted within rift valleys [Talwani et al., 1971]. Further studies have shown that gabbroids may contribute to the surface magnetic field on a scale that is quite comparable to that of basalts [Kent et al., 1978].

The particulars of how secondary magnetization of oceanic mantle peridotites is formed became a focus of interest after it had been proposed that peridotites, just as basalts

Copyright 2001 by the Russian Journal of Earth Sciences.

Paper number TJE02087.

ISSN: 1681-1208 (online)

The online version of this paper was published 15 June 2002. URL: http://rjes.wdcb.ru/v04/tje02087/tje02087.htm and gabbroids, contribute essentially to the dimension and shape of M-anomalies in the oceanic lithosphere [Dunlop and Prevot, 1982; Nazarova and Gorodnitsky, 1986; Nguen and Pechersky, 1989]. By now, a considerable amount of data on petromagnetic characteristics of oceanic peridotites have been amassed [Burakov et al., 1989; Dunlop and Prevot, 1982; Popov and Shcherbakov, 1996; and others]. However, differences in the values of individual petromagnetic parameters are quite considerable even within series of rocks from the same locality, and their average values vary from locality to locality [Popov and Shcherbakov, 1996]. Although it is a unanimous belief that magnetization of oceanic peridotites is coupled to their serpentinization (see the review in [Popov and Shcherbakov, 1996]), nobody has thus far managed to quantify the correlation between the character and degree of serpentinization of peridotites on the one hand and the values of their petromagnetic characteristics on the other.

The collection of peridotites studied in this work was assembled in such manner as to link, with minimal uncertainty, petromagnetic characteristics of the rocks to their metamorphic features while covering a sufficient number of localities in a variety of tectonic settings within the Mid- 


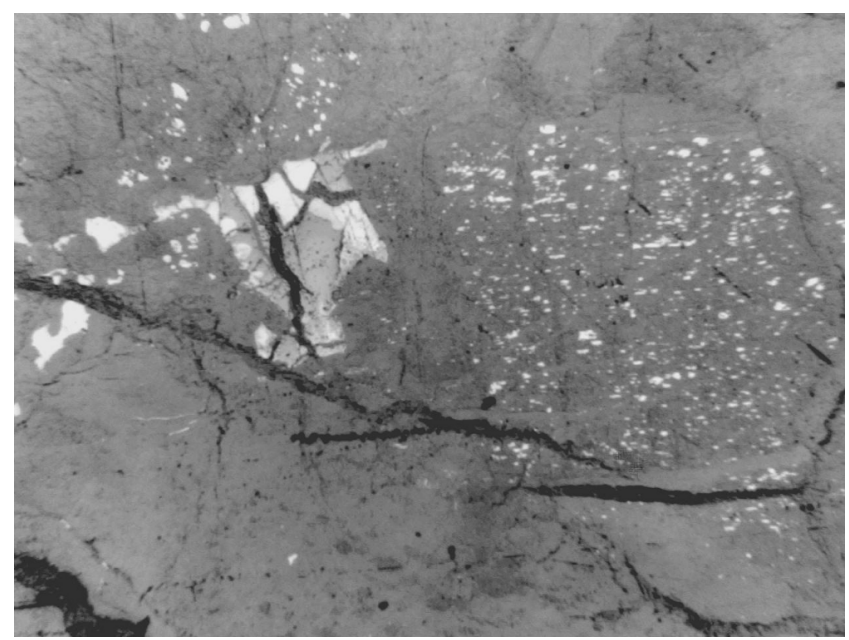

Figure 1. Replacement of primary spinel (light gray) by ferritchromite (white) and segregation of small ferritchromite grains along cleavage in replaced orthopyroxene (bastite) Smp. ABP16-41-3, reflected light, 2-mm field of vision.

Atlantic Ridge. The objective posed was to validate or disprove, based on a representative data set, certain previously proposed assumptions concerning relations between the petrology and petromagnetic properties of oceanic peridotites [Dunlop and Prevot, 1982; Gorodnitsky and Popov, 2000; Nguen and Pechersky, 1989; Pechersky and Didenko, 1995; Pechersky et al., 1993; Popov and Shcherbakov, 1996], namely:

1) Magnetization of oceanic peridotites is of a chemical nature and occurs during their serpentinization.

2) Variations in the abundance, mean grain size, and oxidation degree of the magnetic phase (magnetite) in the MAR peridotites are controlled by characteristics of serpentinization of the rocks.

3) The values of the above parameters differ systematically between peridotites from the rift valley and from the valleys of transform faults.

\section{Principal Stages of Metamorphic Recrystallization of MOR Mantle Peridotites}

Igneous rocks, including peridotites, in the lithosphere of mid-oceanic ridges suffer retrogressive metamorphism [Bazylev et al., 1990; Silantiev, 1995], peridotites being characterized by especially protracted and multistage metamorphic recrystallization, pronounced in the following sequential changes: (i) subsolidus recrystallization of the rocks (above $800^{\circ} \mathrm{C}$ ) [Bazylev and Silantiev, 2000], (ii) mediumtemperature metamorphism $\left(800-450^{\circ} \mathrm{C}\right)$ [Bazylev, 1989, 1992, 1997, 2000; Bazylev et al., 1990; Kimball et al., 1985], (iii) serpentinization of peridotites $\left(350-150^{\circ} \mathrm{C}\right)$ [Bazylev, 1989; Bonatti et al., 1984; Prinz et al., 1976], (iv) carbonatization $\left(30-0^{\circ} \mathrm{C}\right)$, and $(\mathrm{v})$ underwater weathering $\left(0-5^{\circ} \mathrm{C}\right)$.
Thermodynamic data indicate that medium-temperature metamorphism of peridotites, which predates their serpentinization (at temperatures as high as $600-450^{\circ} \mathrm{C}$ ), must already be accompanied by crystallization of secondary spinels of the ferritchromite-magnetite series [Sack and Ghiorso, 1991], which are ferrimagnetics. Such spinels are actually found in oceanic peridotites [Bazylev, 1992, 1997, 2000; Bazylev et al., 1990].

Usually, they appear as primary, translucent Cr-spinel grains being replaced in patches by opaque metamorphic spinel, more lightly colored in reflected light (Figure 1 and photographs in [Bazylev, 1989]), as segregations of ferritchromite grains arranged in chains along cleavage in bastite (Figure 1), or, less frequently, as aggregates of separate comparatively large equant grains of chromian magnetite and magnetite (see photographs in [Bazylev, 2000]).

It was these facts that put to doubt the viability of the above assumptions and drew the focus of attention to medium-temperature recrystallization of MOR peridotites as a likely factor responsible for the peculiarity of their petromagnetic characteristics.

\section{Techniques Used in Assessing the Character and Degree of Recrystallization of Oceanic Peridotites}

During medium-temperature recrystallization of homogeneous oceanic peridotites, orthopyroxene and clinopyroxene in them are replaced by $\mathrm{Ca}$-amphibole and chlorite, as well as by small amounts of talc; olivine is not replaced and shows only sporadic traces of recrystallization [Bazylev, 1992, 2000; Bazylev et al., 1990]. Along the contact with gabbroids, medium-temperature recrystallization of peridotites is accompanied by massive input of silica and is pronounced in talcification of olivine, to the degree of its complete replacement [Bazylev, 1997], although the assemblage of metamorphic silicates remains the same: Ca-amphibole, chlorite, and talc.

The silicates formed in the course of medium-temperature recrystallization of oceanic peridotites survive only at the first stage of serpentinization of the rocks, usually to be completely replaced by serpentine during subsequent stages. For this reason, the most reliable evidence of mediumtemperature recrystallization of oceanic peridotites is the presence of metamorphic Cr-spinels in them (Figure 1); at a certain degree of this recrystallization, textural features of the rocks must be taken into account. Thus, complete serpentinization of orthopyroxene with preservation of abundant olivine relics implies that orthopyroxene was replaced by medium-temperature silicates already prior to the onset of serpentinization of the rocks [Bazylev, 2000]. The aspect of bastites in such rocks is also telling: they are non-homoaxial and consist of an aggregate of rather large variously oriented serpentine flakes (Figure 2).

In quantifying the degree of medium-temperature metamorphic recrystallization of oceanic peridotites, we were guided by the following criteria: 
$0 \%$ - peridotites contain no relics of medium-temperature silicates; all bastites are homoaxial; primary Cr-spinel grains have no traces of replacement by ferritchromite; serpentines have ordinary structures.

$5 \%$ - all the bastites in the rocks are homoaxial; sporadic relics of medium-temperature silicates or patchy replacement of primary spinels are present; serpentines have ordinary structures.

$10 \%$ - clearly manifested replacement of primary spinels by ferritchromite; non-homoaxial bastites after pyroxenes are widespread, but normal bastites prevail.

$20 \%$ - primary spinels survive only as relics in ferritchromites; homoaxial and non-homoaxial bastites after pyroxenes are equally abundant. The rocks often exhibit linear foliation zones, where primary Cr-spinels are replaced particularly intensively.

$30 \%$ - metamorphic spinels (ferritchromites) sharply prevail over primary Cr-spinel relics, and non-homoaxial bastites, over homoaxial ones; the rocks either contain foliation zones or have foliated or thin-banded structures.

$40 \%$ - a virtually extreme degree of "isochemical" medium -temperature recrystallization of peridotites: a complete replacement of pyroxenes and primary spinels, olivine showing no alteration. Primary Cr-spinel relics are often totally absent, and all bastites are non-homoaxial. The rocks are commonly schistose or thin-banded in structure and fine-grained in texture; pyroxene (bastite) grains are cigar-shaped.

$100 \%$ - the maximum degree of recrystallization of peridotites under non-isochemical recrystallization with talcification of olivine. Primary Cr-spinel relics are often absent, and relics of flaky talc aggregates are rather common. Characteristic is lamellar or flaky texture of groundmass serpentine, corresponding to "interlocking and interpenetrating textures" as per [Wicks and Plant, 1979; Wicks and Whittaker, 1977].

The process of serpentinization of oceanic peridotites can be divided into several stages. At the first stage, yellowish green mesh serpentine develops after olivine, and yellowish green bastite (not strictly homoaxial) after pyroxenes, usually along grain margins only [Bazylev, 1989]. At this stage (which can still be called the stage of development of green serpentines, or the stage of mesh serpentinization), peridotites usually retain relics of all the silicatesiboth primary and medium-temperature metamorphic - the degree of serpentinization nowhere reaching $100 \%$. Serpentines at this stage develop after the other silicates and have no traces of recrystallization (growth of plates and accompanying extensive segregation of magnetite grains). At the second stage of serpentinization, as serpentines develop after silicates, the previously formed serpentines begin recrystallizing, usually with segregation of magnetite grains. Serpentines are nonuniform both in aspect and in composition, the degree of serpentinization of rocks usually being 95-100\%. At the third stage, all the serpentines in peridotites are distinctly recrystallized into colorless flakes and plates, the rocks contain abundant small grains of magnetite, the degree of serpentinization of the rocks usually equaling $100 \%$ (this stage can be termed the stage of development of colorless serpentines). Serpentine developing directly after pyroxenes leads to the formation of homoaxial bastites with uniform extinc-

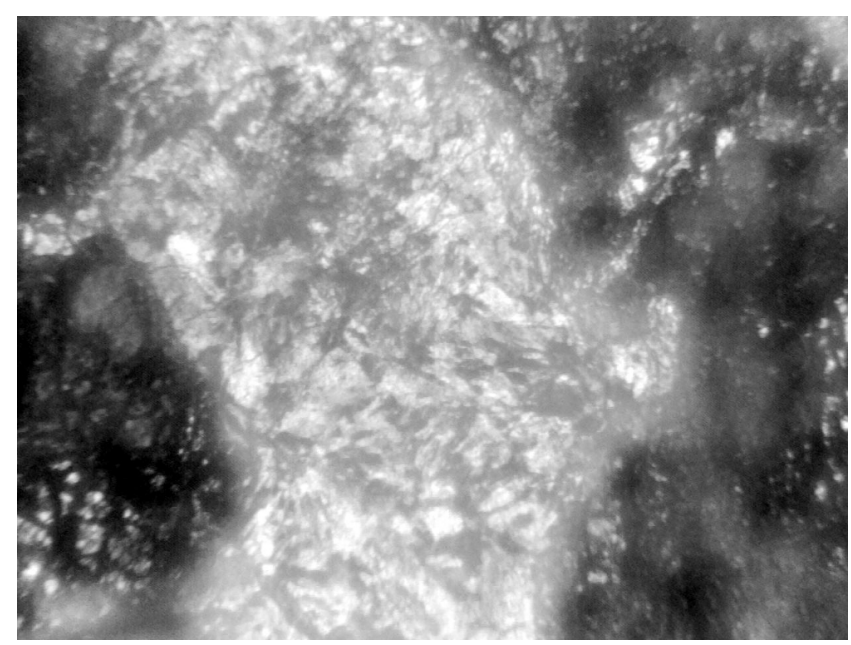

Figure 2. Non-homoaxial bastite barren of pyroxene relics in comparatively fresh olivine. Smp. ABP16-41-18, transmitted light, crossed nicols, 4-mm field of vision.

tion across the entire grain of replaced pyroxene.

Quantitative or semiquantitative assessment of the degree of serpentinization of oceanic peridotites presents no difficulty and can readily be carried out visually in thinsection based on the proportion of non-serpentinized silicates. The degree of serpentinization of peridotites with negligible amounts of aragonite, talc, and amphibole can be estimated from losses on ignition in bulk-rock analyses. (In $100 \%$ serpentinized rocks, this value averages 13.5 wt \%.)

\section{Sampling Locations and Brief Petrographic Description of Peridotites}

This paper presents petromagnetic characteristics of 26 samples from 14 localities near the axis of the Mid-Atlantic Ridge, collected on the cruises of the R/V Akademik Boris Petrov (dredge hauls) and the R/V Faranaut (samples collected by the manned submersible Nautile).

1. The north wall of the Oceanographer FZ (Cruise 12 of the $\mathrm{R} / \mathrm{V}$ Akademik Boris Petrov, Dredge $1,35^{\circ} 23^{\prime} \mathrm{N}$, $\left.35^{\circ} 56^{\prime} \mathrm{W}\right)$.

ABP12-1-5. Grayish cream-colored amphibole-talc rock (metaharzburgite). The degree of medium-temperature recrystallization is $100 \%$, and the degree of serpentinization, $10 \%$.

ABP12-1-7, ABP12-1-9. Greenish spinel harzburgites, unweathered. The degree of medium-temperature recrystallization is weak $(0-5 \%)$, the degree of serpentinization is $100 \%$

ABP12-1-14, ABP12-1-16. Yellowish black spinel harzburgites, weathered. The degree of medium-temperature recrystallization is weak (0-5\%); serpentinization degree, $100 \%$.

2. The north wall of the Hayes FZ (Cruise 16 of the $\mathrm{R} / \mathrm{V}$ Akademik Boris Petrov, Dredge 25, 33 $\left.40^{\prime} \mathrm{N}, 38^{\circ} 54^{\prime} \mathrm{W}\right)$. The character of metamorphism, mineral composition, and rock geochemistry are detailed in [Bazylev, 1997]. 


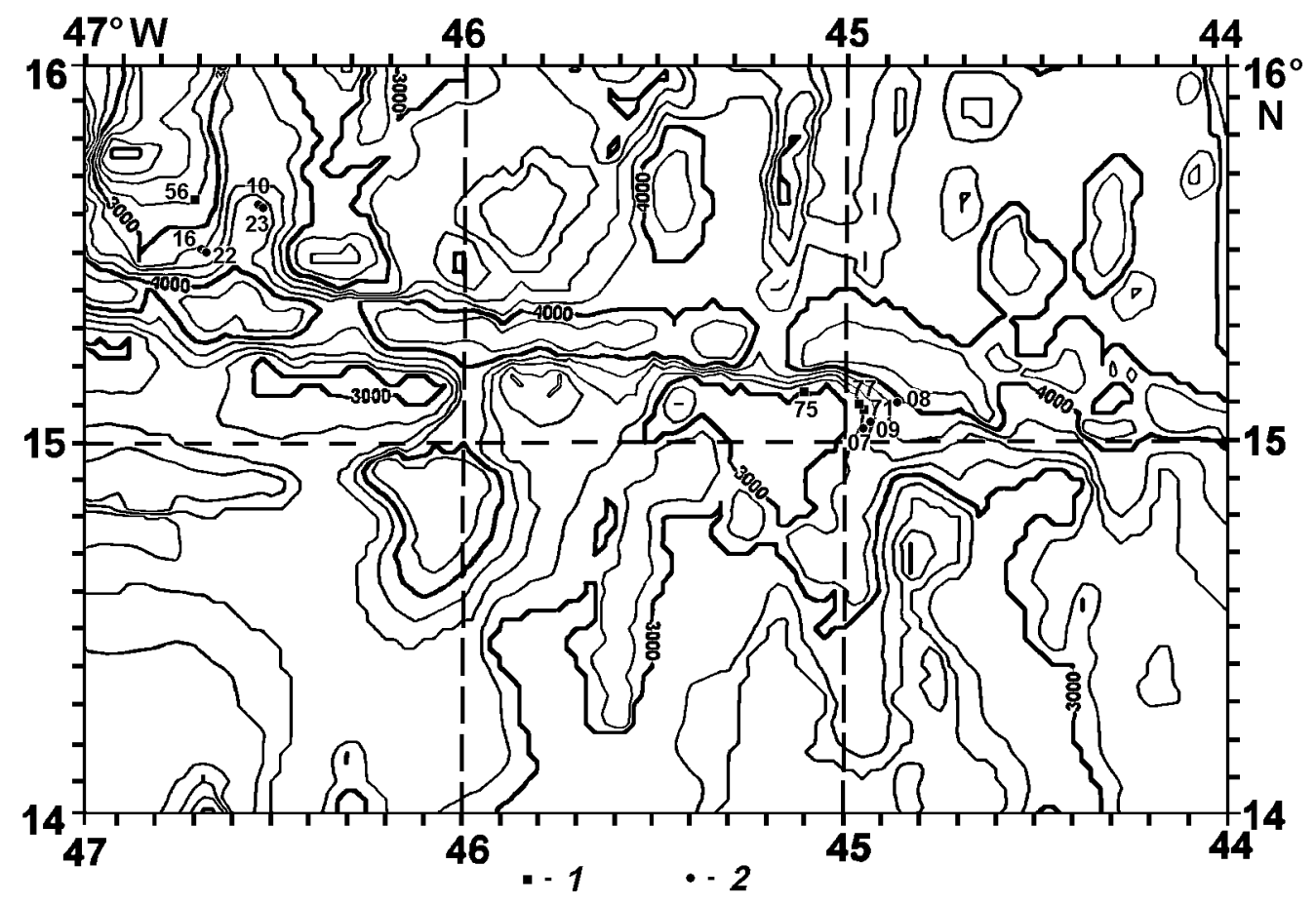

Figure 3. Location of dredge stations (1) and submersible sampling sites (2) on the $15^{\circ} 20^{\prime} \mathrm{N}$ Fracture Zone, Mid-Atlantic Ridge.

ABP16-25-2. Dark green serpentine-talc rock (metaharzburgite). The degree of medium-temperature recrystallization, $100 \%$; the degree of subsequent serpentinization, $60 \%$.

ABP16-25-4. Light green talcite with amphibole (metaharzburgite). The degree of medium-temperature recrystallization, $100 \%$; the degree of subsequent serpentinization, $0 \%$.

3. The north wall of the Atlantis FZ (Cruise 16 of the R/V Akademik Boris Petrov, Dredge $\left.41,30^{\circ} 03^{\prime} \mathrm{N}, 42^{\circ} 09^{\prime} \mathrm{W}\right)$. Some information on the character of metamorphism and mineral composition of the rocks is given in [Bazylev, 1992].

ABP16-41-1. Fresh greenish spinel harzburgite. The degree of medium-temperature recrystallization, $30 \%$, and of subsequent serpentinization, $80 \%$.

ABP16-41-3. Fresh greenish spinel harzburgite. The degree of medium-temperature recrystallization, $30 \%$, and of subsequent serpentinization, $75 \%$.

4. The $15^{\circ} 20^{\prime} \mathrm{N}$ FZ. Location of dredge hauls and sampling stations is shown in Figure 3. Information on the character of metamorphism and mineral composition of peridotites from this locality of the MAR is given in [Bazylev, 2000].

4a. Western wall of the rift valley north of the Fracture Zone (Cruise 16 of the R/V Akademik Boris Petrov, Dredge $\left.56,15^{\circ} 38^{\prime} \mathrm{N}, 46^{\circ} 42^{\prime} \mathrm{W}\right)$.

ABP16-56-10. Yellowish brown weathered spinel harzburgite. The degree of medium-temperature recrystallization, $30 \%$, and of subsequent serpentinization, $99 \%$. Yellow mesh serpentine is developed after olivine.
ABP16-56-68. Bluish gray fresh spinel harzburgite. The degree of medium-temperature recrystallization, 30\%, and of subsequent serpentinization, $100 \%$. Colorless platy serpentine with abundant magnetite is developed after olivine.

ABP16-56-77. Dark grayish green fresh spinel harzburgite. The degree of medium-temperature recrystallization, $20 \%$, and of serpentinization, $100 \%$.

ABP16-56-80. Dark grayish green fresh spinel harzburgite. The degree of medium-temperature recrystallization, $30 \%$, and of serpentinization, $100 \%$.

4b. Same locality (Dives 10 and 23 of the submersible Nautile, $\left.15^{\circ} 37^{\prime} \mathrm{N}, 46^{\circ} 35^{\prime} \mathrm{W}\right)$.

FR10-08. Dark grayish green fresh spinel harzburgite. The degree of medium-temperature recrystallization, $20 \%$, and of serpentinization, $100 \%$.

FR23-02. Dark greenish gray spinel harzburgite. The degree of medium-temperature metamorphic recrystallization, $30 \%$, and of serpentinization, $100 \%$.

4c. Eastern wall of the rift valley to the north of the fracture zone (Dives 16 and 22 of the submersible Nautile, $\left.15^{\circ} 31^{\prime} \mathrm{N}, 46^{\circ} 41^{\prime} \mathrm{W}\right)$.

FR16-07. Dark grayish green thin-banded (mylonitized) spinel harzburgite. The degree of medium-temperature recrystallization, $40 \%$, and of serpentinization, $100 \%$.

FR22-05. Yellowish gray spinel dunite. The degree of medium-temperature recrystallization, 30\%, and of serpentinization, $100 \%$.

$4 \mathrm{~d}$. Southern wall of the fracture zone in its active segment (Cruise 16 of the R/V Akademik Boris Petrov, Dredge 75, $\left.15^{\circ} 08^{\prime} \mathrm{N}, 45^{\circ} 06^{\prime} \mathrm{W}\right)$. 
ABP16-75-72. Greenish gray spinel harzburgite, fresh. No signs of medium-temperature recrystallization; serpentinization degree, $100 \%$.

4e. The bottom of the south segment of the rift valley near its junction with the transform fault valley (Dive 08 of the submersible Nautile, $15^{\circ} 06^{\prime} \mathrm{N}, 44^{\circ} 52^{\prime} \mathrm{W}$ ).

FR08-06 Yellowish gray spinel harzburgite. No signs of medium-temperature recrystallization; the degree of serpentinization, $80 \%$.

FR08-10. Dark gray to black harzburgite-dunite. A moderate degree of medium-temperature recrystallization (10\%); the degree of serpentinization, $99 \%$.

4f. Southern inner corner high of the fracture zone (Cruise 16 of the R/V Akademik Boris Petrov, Dredge $71,15^{\circ} 05^{\prime} \mathrm{N}$, $\left.44^{\circ} 57^{\prime} \mathrm{W}\right)$.

ABP16-71-176. Yellowish gray fresh spinel harzburgite. The degree of medium-temperature recrystallization is low (5\%), and of subsequent serpentinization, $60 \%$.

ABP16-71-188. Yellowish gray fresh spinel harzburgite. The degree of medium-temperature recrystallization is low, and of serpentinization, $80 \%$. The rock contains accessory awaruite [Bazylev, 2000].

$4 \mathrm{~g}$. Same locality (Cruise 16 of the $\mathrm{R} / \mathrm{V}$ Akademik Boris Petrov, Dredge $\left.77,15^{\circ} 06^{\prime} \mathrm{N}, 44^{\circ} 58^{\prime} \mathrm{W}\right)$.

ABP16-77-30. Fresh spinel harzburgite. The degree of medium-temperature metamorphic recrystallization is variable, and that of subsequent serpentinization, $70 \%$.

ABP16-77-113. Dark gray spinel dunite. The degree of medium-temperature metamorphic recrystallization is variable, and that of subsequent serpentinization, $95 \%$.

4f. The west slope of the rift valley to the south of the fracture zone (Dive 07 of the submersible Nautile, $15^{\circ} 02^{\prime} \mathrm{N}$, $44^{\circ} 57^{\prime} \mathrm{W}$; Dive $\left.09,15^{\circ} 03^{\prime} \mathrm{N}, 44^{\circ} 56^{\prime} \mathrm{W}\right)$.

FR07-13. Greenish gray spinel harzburgite, slightly weathered. The degree of medium-temperature recrystallization, 30\%, and of serpentinization, $100 \%$.

FR09-02. Yellow weathered spinel harzburgite. No signs of medium-temperature recrystallization; the degree of serpentinization, $90 \%$.

Therefore, not only do peridotites of the collection under study represent various geodynamic settings within the MAR, but they also reflect the broadest possible range of the degree of medium-temperature recrystallization and serpentinization (Figure 4). Among them, three principal groups can be recognized: (A) metasomatites $(100 \%$ medium-temperature recrystallization, small degree of serpentinization), (B) strongly metamorphosed peridotites (25$40 \%$ medium-temperature recrystallization), and (C) weakly metamorphosed peridotite (less than 25\% mediumtemperature recrystallization).

\section{Petromagnetic Characteristics of Peridotites}

Magnetic properties of the rocks were studied at the Borok Geophysical Observatory of the United Institute of Physics of the Earth, Russian Academy of Sciences. Mea-

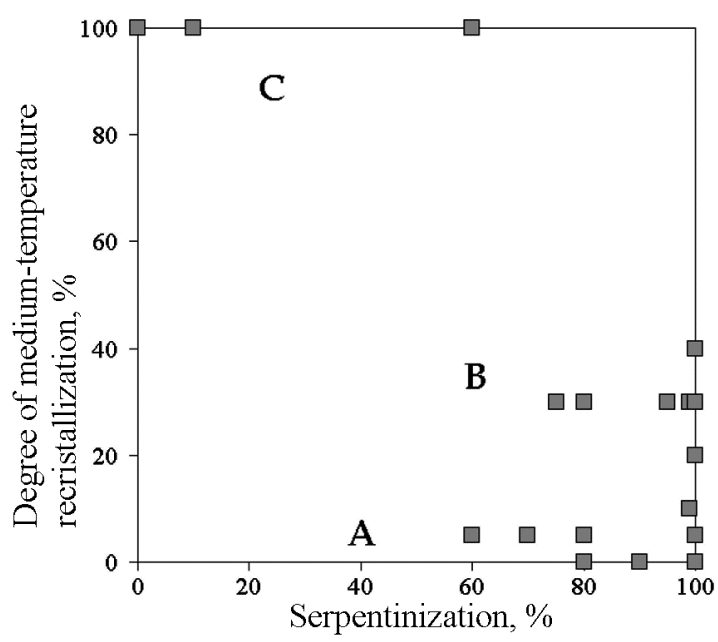

Figure 4. Variations in the degree of medium-temperature recrystallization and serpentinization of peridotites under study. A - metasomatites, B - strongly metamorphosed peridotites, and $\mathrm{C}$ - weakly metamorphosed peridotites.

surements of the natural remanent magnetization In were carried out on an astatic magnetometer, and the saturation magnetization $I s$, the remanent saturation magnetization Irs, the coercive force $H c$, and the remanent coercive force $\mathrm{Hcr}$ were measured on a vibromagnetometer. $I s(T)$ curves were recorded and Curie temperatures determined on a thermomagnetometer as the samples were heated to $650-700^{\circ} \mathrm{C}$; the value of the median demagnetizing field $H \mathrm{H}$ was estimated while removing $I n$ in an alternating magnetic field $H$.

Based on the measurements results Table 1 was composed, which brings together magnetic characteristics of the rocks and their petrographic features; besides, Koenigsberger, Irs/Is, and $\mathrm{Hcr} / \mathrm{Hc}$ ratios were calculated, in order to determine the domain state of ferrimagnetics and the mean integrated grain size of the magnetic phase. For the purposes of comparing magnetic characteristics of the rocks with their petrographic features, it is rewarding to transform the purely magnetic characteristics into those that would reflect physical and chemical parameters of the rocks: the content of the magnetic phase, its compositional peculiarities, and mean integrated grain size.

\section{Relative and Absolute Content of the Magnetic Phase}

The content of a magnetic phase in peridotites can be inferred from the measured values of magnetic susceptibility and saturation magnetization of a sample. The dependency of absolute content of a ferrimagnetic in a rock (in vol \%) on the value of magnetic susceptibility (in SI units), according to [Shcherbakov et al., 1996], can be presented in the form

$$
C \sim \kappa /(1 \div 15)
$$


Table 1. Petromagnetic characteristics of oceanic peridotites

\begin{tabular}{|c|c|c|c|c|c|c|c|c|c|c|c|c|}
\hline Sample & $\begin{array}{c}\mathrm{In}, \\
\mathrm{A} / \mathrm{m}\end{array}$ & $\begin{array}{l}k \times 10^{3}, \\
\text { SI units }\end{array}$ & Q & $\begin{array}{c}I s \times 10^{-3}, \\
\mathrm{~A} / \mathrm{m}\end{array}$ & $\begin{array}{c}\text { Irs } \times 10^{-3}, \\
\mathrm{~A} / \mathrm{m}\end{array}$ & $I r s / I s$ & $\begin{array}{l}H c, \\
\mathrm{mTl}\end{array}$ & $\begin{array}{l}\text { Hcr, } \\
\mathrm{mTl}\end{array}$ & $H c r / H c$ & $\begin{array}{l}H m, \\
\mathrm{mTl}\end{array}$ & $T c,{ }^{\circ} \mathrm{C}$ & Ist/Iso \\
\hline ABP12-1-14 & 0.57 & 21.2 & 0.68 & 6.07 & 1.47 & 0.24 & 26.9 & 45.9 & 1.70 & 37.0 & 595 & 0.43 \\
\hline ABP12-1-16 & 1.46 & 23.9 & 1.54 & 6.08 & 1.64 & 0.27 & 25.4 & 36.7 & 1.45 & 30.0 & 587 & 0.44 \\
\hline ABP12-1-5 & 0.03 & 0.88 & 0.85 & 0.05 & 0.01 & 0.20 & 9.6 & 18.4 & 1.92 & n.d. & n.d. & 0.42 \\
\hline ABP12-1-7 & 1.22 & 55.7 & 0.52 & 8.85 & 1.92 & 0.22 & 13.8 & 22.4 & 1.62 & 15.7 & 575 & 0.76 \\
\hline ABP12-1-9 & 1.23 & 33.6 & 0.92 & 6.45 & 1.60 & 0.25 & 24.4 & 42.9 & 1.76 & 30.0 & 593 & 0.65 \\
\hline ABP16-25-2 & 13.30 & 285.9 & 1.15 & 25.10 & 3.05 & 0.12 & 8.4 & 18.7 & 2.22 & 15.1 & 583 & 0.94 \\
\hline ABP16-25-4 & 2.66 & 103.3 & 0.68 & 10.30 & 1.38 & 0.14 & 12.6 & 30.0 & 2.39 & 23.0 & 587 & 0.89 \\
\hline ABP16-41-1 & 0.88 & 17.0 & 1.30 & 2.57 & 0.70 & 0.27 & 23.5 & 38.0 & 1.62 & 25.5 & 570 & 0.53 \\
\hline ABP16-41-3 & 0.52 & 23.9 & 0.75 & 0.94 & 0.15 & 0.16 & 12.1 & 27.7 & 2.28 & 25.0 & 573 & 0.75 \\
\hline ABP16-56-10 & 0.36 & 21.0 & 0.40 & 3.69 & 0.13 & 0.036 & 5.3 & 20.0 & 3.79 & 8.0 & 593 & 0.81 \\
\hline ABP16-56-68 & 0.63 & 43.6 & 0.36 & 6.73 & 0.29 & 0.04 & 5.4 & 19.4 & 3.57 & 7.5 & 575 & 0.76 \\
\hline ABP16-56-77 & 2.89 & 44.6 & 1.63 & 5.00 & 1.17 & 0.24 & 20.7 & 32.8 & 1.58 & 16.0 & 575 & 0.88 \\
\hline ABP16-56-80 & 0.70 & 43.5 & 0.40 & 6.38 & 0.50 & 0.08 & 8.3 & 21.6 & 2.60 & 13.9 & 575 & 0.85 \\
\hline ABP16-71-176 & 0.48 & 15.5 & 0.80 & 1.88 & 0.47 & 0.25 & 16.6 & 27.6 & 1.66 & 18.0 & 586 & 0.67 \\
\hline ABP16-71-188 & 0.77 & 10.8 & 1.80 & 3.04 & 0.97 & 0.32 & 22.2 & 34.0 & 1.53 & 22.0 & 594 & 0.57 \\
\hline ABP16-75-72 & 2.27 & 26.6 & 2.10 & 4.00 & 1.03 & 0.26 & 24.9 & 41.6 & 1.67 & n.d. & 592 & 0.29 \\
\hline ABP16-77-113 & 3.15 & 34.4 & 2.30 & 5.41 & 0.57 & 0.11 & 10.2 & 23.1 & 2.28 & 14.8 & 575 & 0.42 \\
\hline ABP16-77-30 & 0.11 & 4.0 & 0.69 & 0.37 & 0.06 & 0.16 & 10.6 & 22.0 & 2.07 & 20.0 & 592 & 0.41 \\
\hline FR07-13 & 1.14 & 23.6 & 1.20 & 4.23 & 0.76 & 0.18 & 15.7 & 30.3 & 1.93 & 21.0 & 585 & 0.35 \\
\hline FR08-06 & 1.04 & 16.7 & 1.58 & 2.06 & 0.41 & 0.20 & 14.4 & 23.7 & 1.65 & 15.0 & 586 & 0.41 \\
\hline FR08-10 & 1.02 & 11.2 & 2.30 & 2.05 & 0.51 & 0.25 & 14.3 & 21.8 & 1.52 & 15.0 & 585 & 0.85 \\
\hline FR09-02 & 0.25 & 2.6 & 2.38 & 0.70 & 0.21 & 0.30 & 19.6 & 30.8 & 1.58 & 32.5 & 597 & 0.49 \\
\hline FR10-08 & 2.14 & 28.0 & 1.92 & 3.79 & 1.25 & 0.33 & 28.8 & 43.4 & 1.51 & 32.5 & 580 & 0.67 \\
\hline FR16-07 & 3.28 & 45.6 & 1.72 & 8.27 & 1.79 & 0.22 & 18.1 & 32.2 & 1.78 & 23.0 & 593 & 0.72 \\
\hline FR22-05 & 3.22 & 70.6 & 1.10 & 7.26 & 0.70 & 0.10 & 6.7 & 14.6 & 2.19 & 8.0 & 590 & 0.30 \\
\hline FR23-02 & 5.47 & 57.8 & 2.00 & 7.78 & 1.24 & 0.16 & 12.5 & 22.6 & 1.80 & 10.0 & 575 & 0.80 \\
\hline
\end{tabular}

Notes: In - natural remanent magnetization; $k$ - magnetic susceptibility; $Q$ - Koenigsberger ratio; $I s$ - saturation magnetization; Irs - remanent saturation magnetization; $\mathrm{Hc}$ - coercive force; $\mathrm{Hcr}$ - remanent coercive force; $\mathrm{Hm}$ - the value of the median demagnetizing field; $T c$-Curie temperature; Ist/Iso - the ratio of saturation magnetization measured on heating a sample to $600^{\circ} \mathrm{C}$ vs. the initial saturation magnetization; n.d. - not determined.

although the value of the coefficient in the denominator depends on the domain structure of the ferrimagnetic grains.

From the value of saturation magnetization of a sample, one can in principle determine the content of the magnetic phase more accurately, using the formula

$$
C=I s_{\mathrm{smp}} / I s
$$

where $I s$ is the spontaneous magnetization of the ferrimagnetic, defined by its composition (and which equals $4.85 \times 105 \mathrm{~A} / \mathrm{m}$ for pure magnetite), and $I s_{\mathrm{smp}}$ is the measured saturation magnetization of the sample. The critical issue in this instance is the composition of the ferrimagnetic; e.g., with oceanic peridotites, this is the mole fraction of maghemite in the magnetite-maghemite solid solution, which can be as large as 0.8 [Popov and Shcherbakov, 1996]. In this case, the spontaneous magnetization of the ferrimagnetic decreases to $4.50 \times 10^{5} \mathrm{~A} / \mathrm{m}$.

Nonetheless, the values of the two petromagnetic parameters just mentioned for the peridotites under study are clearly correlative (Figure 5), especially in the region of low and medium values. The existence of this correlation suggests making use of such a parameter as the relative content of the magnetic phase. In so doing, the values of $\kappa$ and Iso corresponding to the maximum content of magnetite in typical oceanic serpentinites without traces of mediumtemperature metamorphism were taken to be unity:

$$
R C 1=\kappa /\left(70.6 \times 10^{-3}\right),
$$

where $70.6 \times 10^{-3}$ is the maximum value of $\kappa$ (in Sample FR22-05), and

$$
R C 2=I \text { so } / 8.85
$$

where $8.85 \times 10^{-3} \mathrm{~A} / \mathrm{m}$ is the maximum value of Iso (in Sample ABP12-1-7). The character of correlations calculated from (3) and (4) for relative contents of the magnetic phase for the collection under study is portrayed in Figure 6. Evidently, the rocks are best represented by the mean arithmetic value

$$
R C=(R C 1+R C 2) / 2 .
$$

Absolute content of the magnetic phase (in vol \%) can be assessed from the formula

$$
A C=1.87 \times 100 \times R C,
$$


which represents calibration of the values of relative contents of the magnetic phase in oceanic peridotites against the absolute contents, calculated from Formula (2), assuming spontaneous magnetization of the ferrimagnetic to be $4.5 \times 10^{5} \mathrm{~A} / \mathrm{m}$ [Popov and Shcherbakov, 1996].

The use of the relative content of the magnetic phase in peridotite instead of absolute content offers certain advantages. Indeed, the content of iron in residual peridotites is roughly constant, varying but slightly with the rock depletion degree [Bazylev, 1989]. The content of iron in serpentine in equilibrium with magnetite is bound to decrease with temperature, in compliance with the phase correspondence principle [Perchuk and Ryabchikov, 1976]. Inasmuch as there is a lower temperature limit to serpentinization of peridotites, defined by kinetic factors [Dmitriev et al., 1999], the content of iron in serpentine from oceanic peridotites also has its lower limit, empirically close to 1.8 wt \% FeO (the serpentine composition is given in [Prinz et al., 1976], and closely similar compositions, in [Bazylev, 1989, 2000]; serpentine in Sample ABP12-1-7 also has a similar composition).

It thus follows that there exists an upper limit to the amount of magnetite that can form during isochemical serpentinization of oceanic mantle peridotites. The value of the relative content of magnetite in the rock illustrates the measure of materialization of this possibility in a specific rock. Values of the relative content of magnetite significantly above unity suggest that the rock is to some extent anomalous: Either the rock was originally enriched in iron (e.g., it was cumulitic or metasomatosed) or at some stage of recrystallization iron was added to the rock, or else, the magnetite contained in the rock originated not through serpentinization of silicates but through their talcification, since talc is lower in iron than serpentine [Bazylev, 1997].

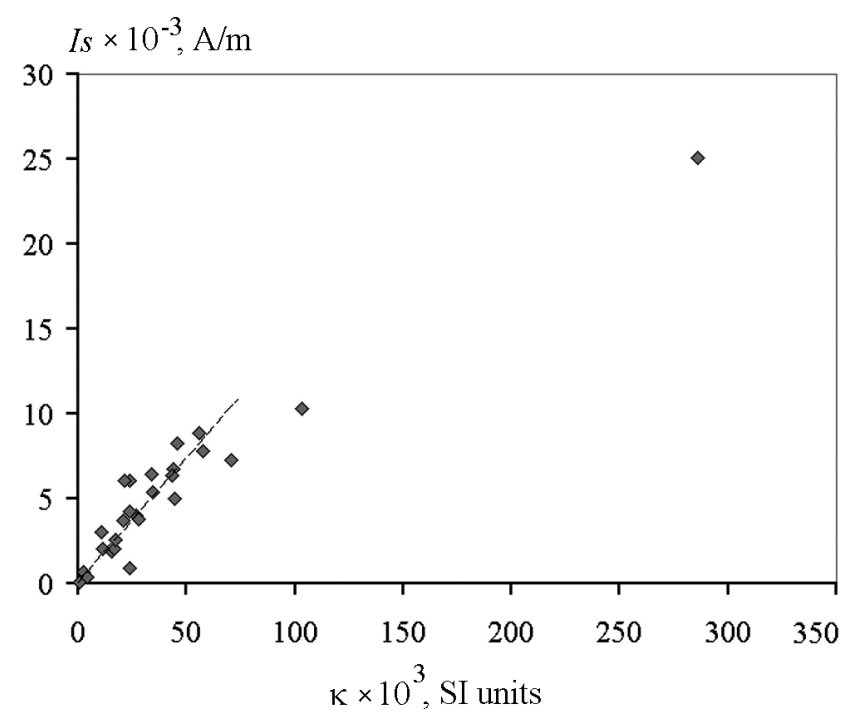

Figure 5. Correlation of petromagnetic parameters reflecting the abundance of magnetic phase: $k$ - magnetic susceptibility, Is - saturation magnetization.

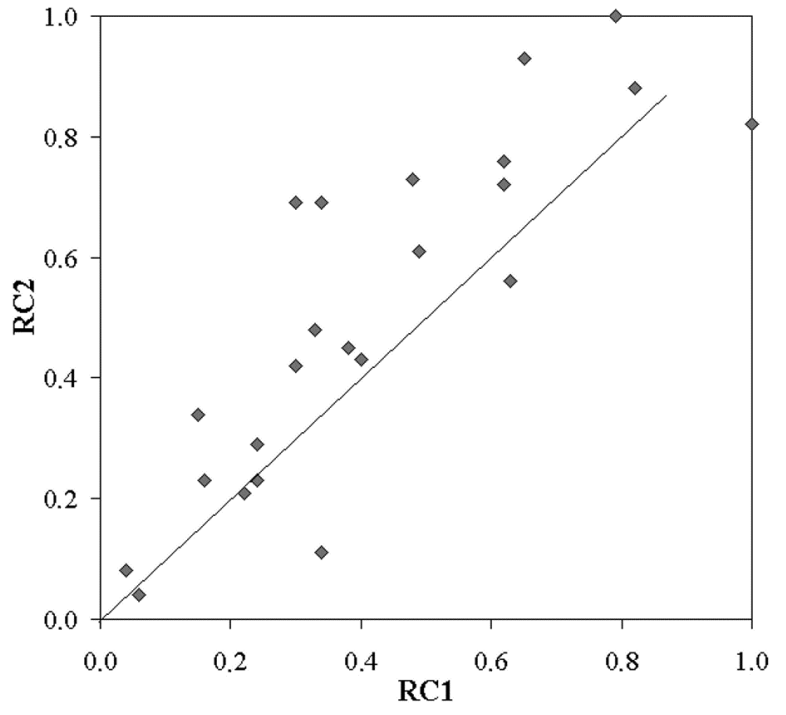

Figure 6. Correlation of parameters reflecting the relative content of magnetic phase in peridotites (metasomatites not plotted).

\section{Relative and Absolute Grain Size of the Magnetic Phase}

The values of some magnetic parameters are known to reflect the mean integrated grain size of the magnetic phase [Dunlop and Prevot, 1982]. Among these parameters, one should note the ratio $R i=I r s / I s$ (remanent saturation magnetization vs. saturation magnetization), the ratio $R h=$ $\mathrm{Hcr} / \mathrm{Hc}$ (coercive force per remanent magnetization unit vs. coercive force), as well as the value of coercive force proper per remanent magnetization $\mathrm{Hcr}$ unit and the value of the Koenigsberger factor Qn [Pechersky and Didenko, 1995; Shcherbakov et al., 1996].

However, the study of the present collection, just as the data in [Dunlop and Prevot, 1982], show the correlation to be strongest for the first two parameters. The value $R i=I r s / I s$ is lowest for the largest grains and highest for the smallest ones, whereas the value $\mathrm{Rh}=\mathrm{Hcr} / \mathrm{Hc}$, vice versa, is highest for the largest grains and lowest for the smallest (Figure 7). Just as with the relative content of magnetic phase, the relative mean size of magnetic particles in a sample can be determined if the value of parameters corresponding to the maximum particle size (among the studied rocks) is taken to be unity, and to the minimum size, to be zero. The strongest correlation of the values of relative grain sizes of the magnetic phase (Figure 8 ) is achieved when the values of $R i$ and $R h$ are used in a logarithmic form:

$$
\begin{aligned}
& R S 1=[\log (0.329)-\log (R i)] / 0.96, \\
& R S 2=[\log (R h)-\log (1.45)] / 0.42 .
\end{aligned}
$$

In six samples from the collection under study, the mean grain size of the magnetic phase remains rather constant within a sample, and it was measured under a microscope: Smp. ABP12-1-5, $20 \mu \mathrm{m}$; Smp. FR08-06, $10 \mu \mathrm{m}$; Smp. 


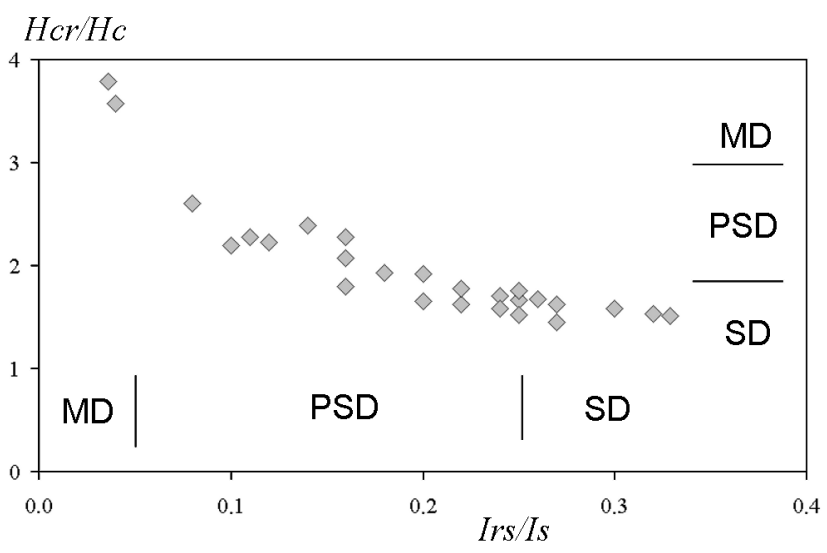

Figure 7. Correlation of petromagnetic parameters reflecting the domain structure (size) of grains of the magnetic phase: $\mathrm{Hcr} / \mathrm{Hc}$ - the ratio of coercive force per remanent magnetization unit to coercive force, Irs/Is the ratio of remanent saturation magnetization to saturation magnetization. $\mathrm{MD}=$ interval characteristic of multidomain grains, PSD = interval characteristic of pseudosingle-domain grains, and $\mathrm{SD}=$ interval characteristic of single-domain grains.

ABP16-71-188, $1 \mu \mathrm{m}$; Smp. FR08-10, $2 \mu \mathrm{m}$; Smp. ABP1656-10, $50 \mu \mathrm{m}$; Smp. ABP16-56-77, $3 \mu \mathrm{m}$. These data permit calibrating the value of the relative grain size (Figure 9):

$$
\log (A S)=1.27 \times \log (R S)+1.8
$$

where $A S$ is the absolute size (in $\mu \mathrm{m}$ ) and $R S$ is the mean relative size (a dimensionless value), assessed from (7) and (8).

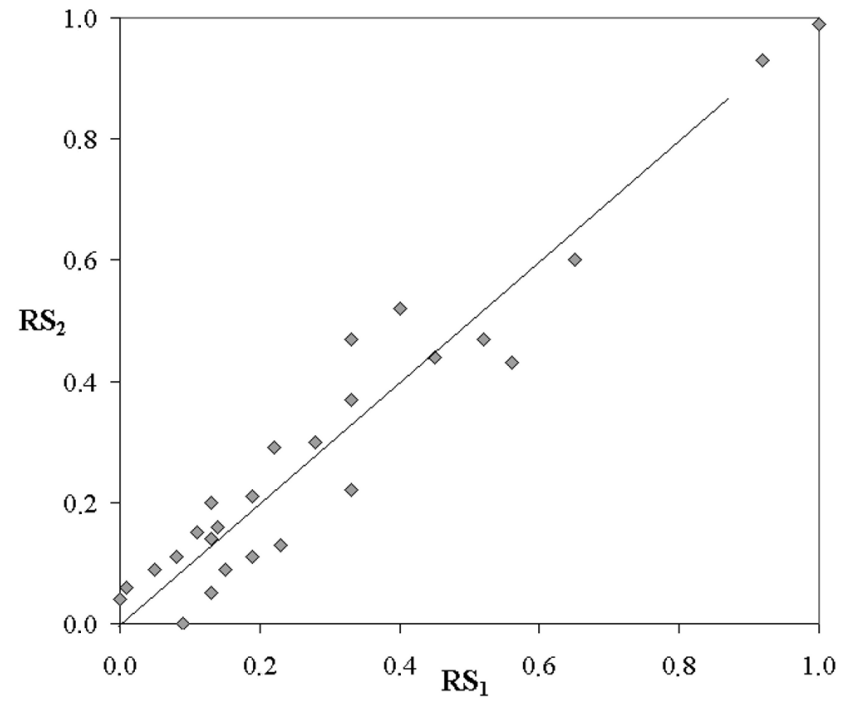

Figure 8. Correlation of parameters reflecting the mean relative grain size of the magnetic mineral.

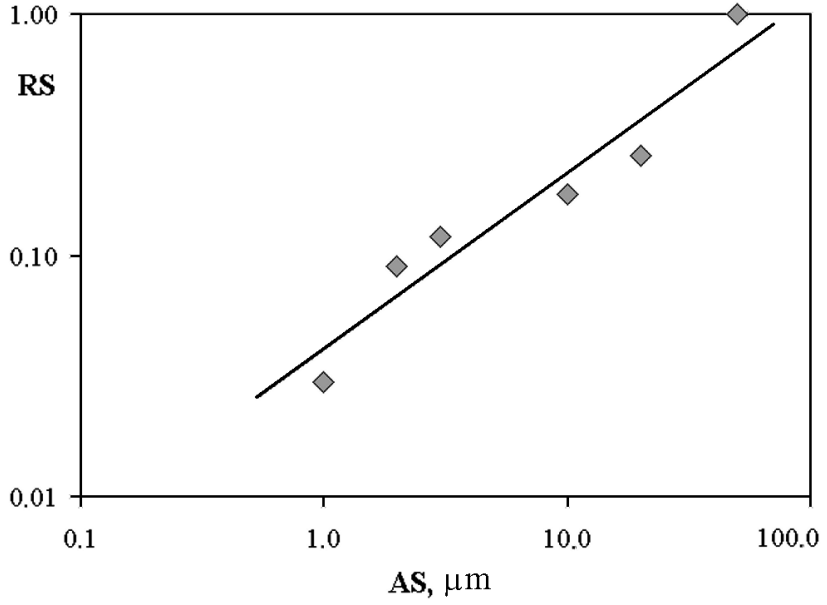

Figure 9. Calibration of absolute mean grain size of the magnetic mineral. AS - absolute size, RS - relative size.

\section{Magnetite Oxidation Degree}

The character of thermodemagnetization curves for oceanic serpentinites suggests that the only magnetic phase in the rocks is magnetite, partially oxidized (a magnetites maghemite solid solution). The maghemite mole fraction can be determined in two waysifrom the temperature corresponding to the Curie point

$$
O D 1=(T c-578) /(675-578)
$$

and from the ratio Ist/Iso (the ratio of the saturation magnetization, measured after heating a sample to $600^{\circ} \mathrm{C}$, to the initial saturation magnetization):

$$
O D 2=1-\text { Ist } / \text { Iso } .
$$

The degrees of magnetite oxidation, calculated from (10) and (11), in the rocks of our collection show virtually no correlation with each other (Table 2). Based on (10), the maghemite mole fraction is no greater than 0.18 , eight of the samples having negative correlations. From (11), maghemite mole fraction ranges $0.06-0.71$. The reasons of this scatter are not clear yet. It might be that the presence in the rocks, alongside magnetite, of some amounts of ferritchromite and Cr-magnetite depresses the integrated value of the Curie point, which is lowest in those samples that underwent intensive medium-temperature metamorphism (ABP16-41-1 and 41-3).

One way or another, the corollary on the possibility of a geodynamic control over the oxidation degree of magnetites (and, accordingly, over the redox conditions of serpentinization) in oceanic peridotites [Gorodnitsky and Popov, 2000] appears somewhat premature. It is more reasonable yet to refrain from using the calculated maghemite mole fraction in the maghemites-magnetite solid solution for theoretical constructions as long as the causes of the mismatch between the values of this parameter assessed by different techniques remain unclear. 
Table 2. Tectonic setting, metamorphic features, number, mean grain size, and degree of oxidation of the magnetic phase in MOR peridotites under study

\begin{tabular}{|c|c|c|c|c|c|c|c|c|c|c|}
\hline Sample & TS & Met., \% & Serp., \% & $\mathrm{SS}$ & $R C$ & $R S$ & $O D 1$ & $O D 2$ & $A C$, vol $\%$ & $A S, \mu \mathrm{m}$ \\
\hline ABP12-1-14 & $\mathrm{FZ}$ & 5 & 100 & $3^{*}$ & 0.49 & 0.15 & 0.16 & 0.58 & 1.01 & 6 \\
\hline ABP12-1-16 & $\mathrm{FZ}$ & 0 & 100 & $3^{*}$ & 0.51 & 0.04 & 0.07 & 0.56 & 1.05 & 1.2 \\
\hline ABP12-1-5 & $\mathrm{FZ}$ & 100 & 10 & 1 & 0.01 & 0.26 & ND & 0.58 & 0.02 & 11 \\
\hline ABP12-1-7 & $\mathrm{FZ}$ & 5 & 100 & 3 & 0.89 & 0.15 & -0.05 & 0.24 & 1.87 & 6 \\
\hline ABP12-1-9 & $\mathrm{FZ}$ & 0 & 100 & 3 & 0.60 & 0.16 & 0.14 & 0.35 & 1.25 & 6 \\
\hline ABP16-25-2 & $\mathrm{FZ}$ & 100 & 60 & 1 & 3.44 & 0.44 & 0.03 & 0.06 & 7.32 & 23 \\
\hline ABP16-25-4 & $\mathrm{FZ}$ & 100 & 0 & 1 & 1.31 & 0.46 & 0.07 & 0.11 & 2.78 & 24 \\
\hline ABP16-41-1 & $\mathrm{FZ}$ & 30 & 80 & 1 & 0.27 & 0.10 & -0.11 & 0.47 & 0.55 & 3 \\
\hline ABP16-41-3 & $\mathrm{FZ}$ & 30 & 75 & 1 & 0.22 & 0.40 & -0.07 & 0.25 & 0.48 & 20 \\
\hline ABP16-56-10 & RV & 30 & 100 & $1^{*}$ & 0.36 & 1.00 & 0.14 & 0.19 & 0.74 & 63 \\
\hline ABP16-56-68 & $\mathrm{RV}$ & 30 & 100 & $2-3$ & 0.69 & 0.93 & -0.05 & 0.24 & 1.44 & 57 \\
\hline ABP16-56-77 & $\mathrm{RV}$ & 20 & 100 & 3 & 0.60 & 0.12 & -0.05 & 0.12 & 1.26 & 4 \\
\hline ABP16-56-80 & $\mathrm{RV}$ & 30 & 100 & 3 & 0.67 & 0.63 & -0.05 & 0.15 & 1.40 & 35 \\
\hline ABP16-71-176 & $\mathrm{CH}$ & 5 & 60 & 1 & 0.22 & 0.13 & 0.06 & 0.33 & 0.45 & 5 \\
\hline ABP16-71-188 & $\mathrm{CH}$ & 0 & 80 & 1 & 0.25 & 0.03 & 0.15 & 0.44 & 0.51 & 0.9 \\
\hline ABP16-75-72 & $\mathrm{FZ}$ & 0 & 100 & 2 & 0.41 & 0.13 & 0.13 & 0.71 & 0.87 & 5 \\
\hline ABP16-77-113 & $\mathrm{CH}$ & 30 & 95 & 1 & 0.55 & 0.49 & -0.05 & 0.58 & 1.15 & 26 \\
\hline ABP16-77-30 & $\mathrm{CH}$ & 5 & 70 & 1 & 0.05 & 0.35 & 0.13 & 0.59 & 0.11 & 17 \\
\hline FR07-13 & RV & 30 & 100 & 2 & 0.41 & 0.29 & 0.05 & 0.65 & 0.84 & 13 \\
\hline FR08-06 & RV & 0 & 80 & 1 & 0.23 & 0.18 & 0.06 & 0.59 & 0.49 & 7 \\
\hline FR08-10 & $\mathrm{RV}$ & 10 & 99 & $2-3$ & 0.20 & 0.09 & 0.05 & 0.15 & 0.40 & 3 \\
\hline FR09-02 & RV & 0 & 90 & $1^{*}$ & 0.06 & 0.07 & 0.18 & 0.51 & 0.12 & 2 \\
\hline FR10-08 & RV & 20 & 100 & 3 & 0.41 & 0.02 & 0 & 0.33 & 0.86 & 0.5 \\
\hline FR16-07 & RV & 40 & 100 & 3 & 0.79 & 0.20 & 0.14 & 0.28 & 1.64 & 8 \\
\hline FR22-05 & RV & 30 & 100 & 3 & 0.91 & 0.49 & 0.11 & 0.70 & 1.93 & 26 \\
\hline FR23-02 & $\mathrm{RV}$ & 30 & 99 & 3 & 0.85 & 0.27 & -0.05 & 0.20 & 1.78 & 12 \\
\hline
\end{tabular}

Notes: TS - sampled tectonic setting: FZ - fracture zone walls and valley, RV - rift valley and its slopes, CH - corner high at the junction of a fracture zone and rift valley; Met - the degree of medium-temperature metamorphic recrystallization of the rock, Serp - serpentinization degree of the rock, SS - serpentinization stage, $R C$ - mean relative content of the magnetic phase, $R S$ mean relative grain size of the magnetic phase, $O D 1$ and $O D 2$ - oxidation degree of magnetite, estimated using different techniques (Formulas (10) and (11), respectively), $A C$ - mean absolute content of magnetic phase (magnetite) calculated using Formula (6), $A S$ - mean absolute grain size of magnetic phase calculated using Formula (9). Asterisk marks heavily weathered samples.

\section{The Effect of Medium-Temperature Recrystallization}

The difficulty of assessing this effect lies if that mediumtemperature metamorphism in oceanic peridotites is almost invariably overprinted by subsequent serpentinization of the rocks, so that its imprint is hard to separate from that of the latter. Nonetheless, the collection under study presents two extraordinary spinel harzburgites, whose primary silicates were completely replaced by talc, amphibole, and chlorite under medium-temperature metamorphism, the degree of subsequent serpentinization of the rocks being negligible. These are samples from the Oceanographer FZ (ABP12-1-5) and Hayes FZ (ABP16-25-4). A rather strong medium-temperature metamorphism (exceeding 30\%), albeit overprinted by subsequent moderate serpentinization of the rocks, is also manifest in Sample ABP16-25-2 and in a sample from the Atlantis FZ, ABP16-41-3 (Table 2).

It turns out that peridotites that experienced extensive medium-temperature metamorphic recrystallization, are characterized by broadly variable (including extremely high) contents of the magnetic phase at a rather large value of its grain size (relative size, $0.3-0.5$ ), which corresponds to some $20 \mu \mathrm{m}$ (Figure 10).

\section{The Effect of Serpentinization}

The impact of mesh serpentinization (the stage of development of green serpentines) is best pronounced in rocks with a degree of medium-temperature recrystallization below 25\% (ABP16-71-176, ABP16-71-188, FR08-06, FR08-10, FR09-02). Overall, the increase in the degree of serpentinization of the rocks during the mesh serpentinization stage is accompanied by a moderate increase in the abundance of the magnetic phase, whose relative content does not exceed 0.25 (Figure 11). The relative size of magnetic grains is small, averaging 0.1 , which corresponds to $3 \mu \mathrm{m}$. It increases somewhat with the degree of serpentinization, but remains below 0.2 . 


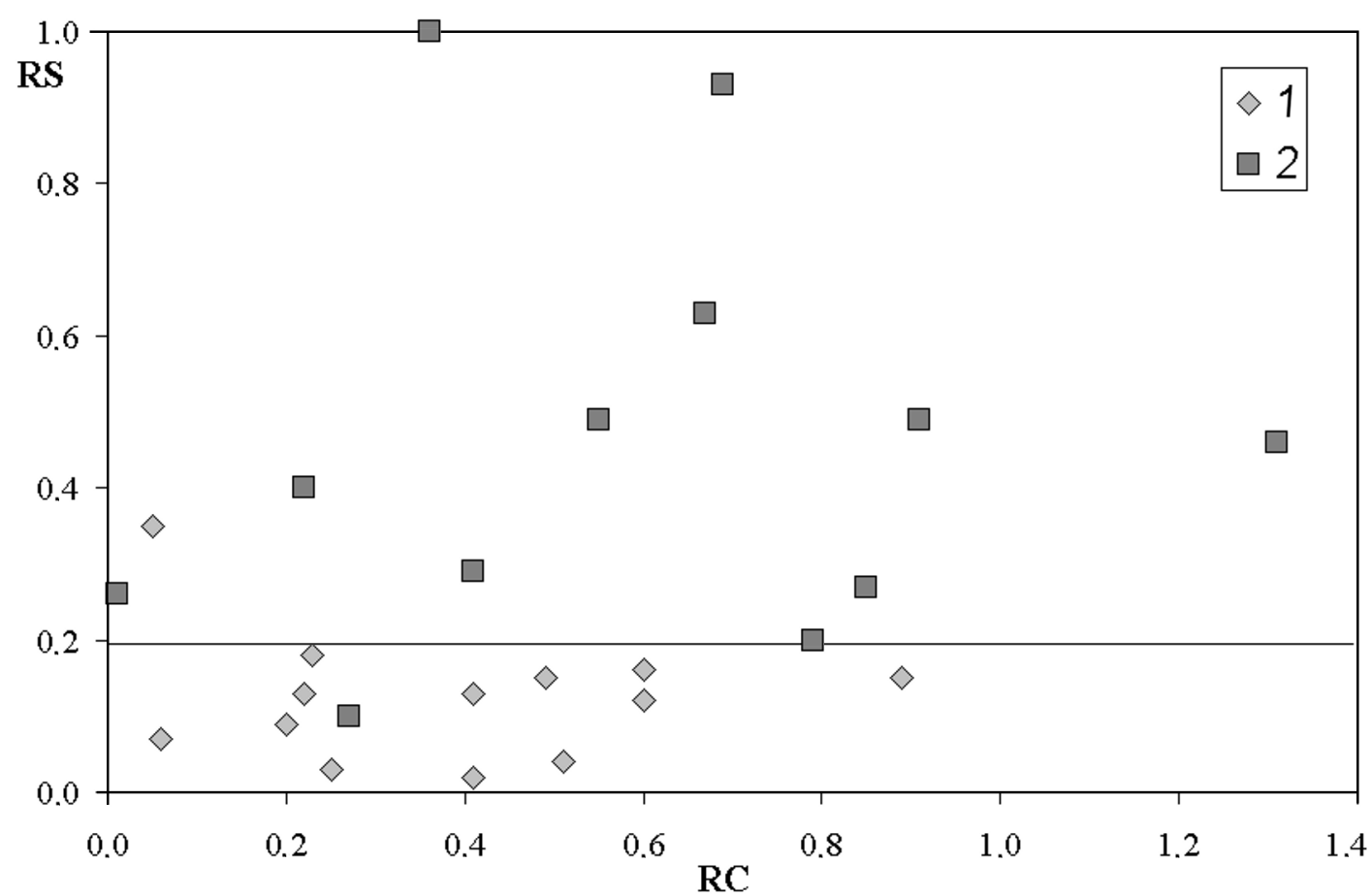

Figure 10. Relative content of magnetic phase (RC) vs. mean relative grain size of magnetic phase (RS) for peridotites under study. 1 - rocks with a medium-temperature metamorphic recrystallization degree below 25\%; 2 - same, above $25 \%$. Strongly metamorphosed peridotites are characterized by an increased mean grain size of the magnetic phase.

Rocks with an increased degree of medium-temperature recrystallization occasionally exhibit an increased relative size of magnetic grains (ABP16-77-30, ABP16-41-3, ABP1656-10) due to the presence of medium-temperature $\mathrm{Cr}$ magnetite, whose impact on magnetic characteristics of the rocks becomes obscured as the degree of serpentinization of the rocks increases owing to the prevalence of small magnetite grains, crystallizing under serpentinization.

The stage of development of colorless serpentines in the rocks is characterized by segregation of considerable amounts of magnetite. In its purest form, this effect is manifest in rocks with weakly developed medium-temperature recrystallization (ABP16-1-7, 1-9, 1-14, 1-16, 56-77, FR10-08). The mean relative size of magnetic grains in these rocks is not large $(0.11$, roughly corresponding to $4 \mu \mathrm{m})$, with the mean relative content of the magnetic phase being 0.6 .

Increased mean sizes of magnetic grains, just as in rocks with green serpentines, are detected only in rocks with intensive (over 25\%) manifestation of the preceding mediumtemperature metamorphic recrystallization.

Therefore, the mean grain size of the magnetite that is formed at various stages of serpentinization of oceanic peridotites is $1-7 \mu \mathrm{m}$, the increase in magnetite content with the degree of rock serpentinization and with the transition to the subsequent serpentinization stage involving no perceptible change in the mean integrated size of magnetite grains in the rocks.

\section{The Effect of Weathering}

To elucidate this effect, we studied two fresh and two weathered serpentinites from the Oceanographer FZ. The only significant distinction of the weathered samples (ABP16-1-14 and 1-16) from the fresh ones (1-7 and 1-9) lies in their decreased relative content of the magnetic phase (0.5 against 0.75$)$, possibly resulting from the magnetitesmaghemite solid solution being partially oxidized or recrystallized to hematite or goethite [Popov and Shcherbakov, 1996]. At the same time, quantification of the oxidation degree of magnetite grains in the rocks (Table 2) reveals no consistency and obviates the conclusion that in weathered samples the oxidation degree of magnetite is higher than in unweathered ones.

\section{Discussion}

The data obtained afford the corollary that the origin of magnetization in oceanic peridotites is due not only to their serpentinization, but also to the preceding mediumtemperature metamorphism of the rocks. The impact of the latter factor on magnetic characteristics of oceanic peridotites had been disregarded. 
Table 3. Estimated mean grain size of magnetic phase in peridotites from various localities on mid-ocean ridges

\begin{tabular}{|c|c|c|c|c|c|c|}
\hline $\begin{array}{l}\text { Dredge station, hole, } \\
\text { submersible dive }\end{array}$ & $\begin{array}{l}\text { Oceanic locality, } \\
\text { fracture zone }\end{array}$ & $\mathrm{TS}$ & $R C$ & $R S$ & $\begin{array}{l}\text { Number } \\
\text { of samples }\end{array}$ & $\begin{array}{l}\text { Data } \\
\text { source }\end{array}$ \\
\hline ABP12-1 & Oceanographer FZ & $\mathrm{FZ}$ & 0.63 & 0.13 & $4^{*}$ & 1 \\
\hline ABP16-25 & Hayes FZ & FZ & 2.38 & 0.45 & 2 & 1 \\
\hline ABP16-41 & Atlantis FZ & $\mathrm{FZ}$ & 0.24 & 0.25 & 2 & 1 \\
\hline ABP16-56 & $15^{\circ} 20^{\prime} \mathrm{N} \mathrm{FZ}$ & $\mathrm{RV}$ & 0.58 & 0.67 & 4 & 1 \\
\hline ABP16-71 & $15^{\circ} 20^{\prime} \mathrm{N} \mathrm{FZ}$ & $\mathrm{CH}$ & 0.23 & 0.08 & 2 & 1 \\
\hline ABP16-75 & $15^{\circ} 20^{\prime}$ N FZ & $\mathrm{FZ}$ & 0.41 & 0.13 & 1 & 1 \\
\hline ABP16-77 & $15^{\circ} 20^{\prime} \mathrm{N} \mathrm{FZ}$ & $\mathrm{CH}$ & 0.30 & 0.42 & 2 & 1 \\
\hline FR07, 09 & $15^{\circ} 20^{\prime} \mathrm{N} \mathrm{FZ}$ & $\mathrm{RV}$ & 0.23 & 0.18 & 2 & 1 \\
\hline FR08 & $15^{\circ} 20^{\prime} \mathrm{N} \mathrm{FZ}$ & $\mathrm{RV}$ & 0.21 & 0.14 & 2 & 1 \\
\hline FR10, 23 & $15^{\circ} 20^{\prime} \mathrm{N} \mathrm{FZ}$ & RV & 0.63 & 0.15 & 2 & 1 \\
\hline FR16, 22 & $15^{\circ} 20^{\prime} \mathrm{N} \mathrm{FZ}$ & $\mathrm{RV}$ & 0.85 & 0.35 & 2 & 1 \\
\hline AMK15, Snake Pit & Cane FZ & $\mathrm{RV}$ & 1.00 & 0.28 & 2 & 2 \\
\hline ANS7, various stations & St. Paul FZ & $\mathrm{FZ}$ & 0.39 & 0.15 & 2 & 2 \\
\hline DM28, Station 2498 & Clarion FZ & $\mathrm{FZ}$ & 0.49 & 0.36 & 7 & 2 \\
\hline Hole 334 & MAR & $(\mathrm{RV})$ & 0.74 & 0.25 & 4 & 3 \\
\hline Hole 395 & Cane FZ & $(\mathrm{RV})$ & 0.29 & 0.43 & 3 & 3 \\
\hline ANS3, various stations & $15^{\circ} 20^{\prime} \mathrm{N} \mathrm{FZ}$ & FZ? & 0.28 & 0.32 & 12 & 2 \\
\hline ANS3, various stations & $15^{\circ} 20^{\prime} \mathrm{N} \mathrm{FZ}$ & FZ? & 0.48 & 0.33 & $?$ & 4 \\
\hline V12, various stations & Gorringe Bank & & 0.54 & 0.16 & 5 & 2 \\
\hline Hole 4 & Gorringe Bank & & 0.79 & 0.28 & 7 & 5 \\
\hline Hole 5 & Gorringe Bank & & 0.70 & 0.11 & 7 & 5 \\
\hline
\end{tabular}

Notes: TS - tectonic setting, $R C$ - relative content of magnetic phase, $R S$ - relative grain size of magnetic phase. ${ }^{*}-$ without metaharzburgite, 1-5 - Data sources: 1, this study; 2, Popov and Shcherbakov [1994]; 3, Dunlop and Prevot [1982]; 4, Burakov et al., [1989]; 5, Popov and Shcherbakov [1996].

Variations in the values of magnetic parameters of MOR peridotites due to the amount of the magnetic phase and its mean integrated size, are controlled by both the character (stage and degree) of serpentinization of the rocks and by the degree of the preceding medium-temperature metamorphism of peridotites.

Using averaged data from various segments of the MOR, increased mean grain sizes of the magnetic mineral, indicative of the medium-temperature metamorphism of peridotites, are established in most sampling localities both as per our own and published data (Table 3, Figure 12). Thus, intensive medium-temperature metamorphic recrystallization, as inferred from magnetic characteristics of the rocks, can be expected in peridotites from the Cane FZ (Snake Pit locality) and from the Clarion FZ, DSDP Holes 334 and 395 (Table 3). This furnishes further evidence for the broad development of medium-temperature metamorphic recrystallization of peridotites within MORs, established previously using petrologic methods [Bazylev and Silantiev, 2000; Bazylev et al., 1990].

The data presented here (Table 3 ) suggest that the variations in tectonic settings of peridotite outcrop localities within MORs (valleys of transform faults versus rift valleys) cause no systematic differences in their magnetic characteristics, contrary to the conclusions in [Gorodnitsky and Popov, 2000]. The issue of likely dissimilarities in recrystallization regimes of peridotites from various tectonic structures in mid-oceanic ridges is therefore open to discussion.
It follows from the obtained data that by the point in time when residual peridotites in the lithosphere of mid-oceanic ridges have cooled down to the temperature corresponding to the Curie point for magnetite or Cr-spinel with a high fraction of the magnetite component (ca. $580^{\circ} \mathrm{C}$ ), they, as a rule, already contain such metamorphic spinel. Hence, the thickness of the lithospheric magnetic layer beneath MOR axes, evidently, is constrained not by the depth of the $350-400^{\circ} \mathrm{C}$ isotherm, as is assumed in the current petromagnetic models for the structure of oceanic lithosphere [Gordin et al., 1993; Gorodnitsky and Shishkina, 1996; Pechersky and Didenko, 1995; Pechersky et al., 1993], but by the $580^{\circ} \mathrm{C}$ isotherm depth. The depth of this isotherm in axial MOR regions, according to geothermal gradient estimates [Bazylev and Silantiev, 2000], may range from 6 to $15 \mathrm{~km}$. This suggests that the uppermost layer of the lithospheric mantle beneath MORs, especially near major transform faults, should also be attributed to the MOR magnetic layer. Therefore, the thickness of the magnetic layer beneath mid-oceanic ridges, evidently, must be essentially greater (at least over certain localities) than 6 to $10 \mathrm{~km}$, values adopted in petromagnetic models for the oceanic lithospheric structure [Banerjee, 1984; Dunlop and Prevot, 1982; Gordin et al., 1993; Gorodnitsky and Shishkina, 1996; Pechersky and Didenko, 1995; Pechersky et al., 1993].

The results obtained in this work permit assessing the temperature and temporal interval in which MOR peridotites acquire secondary magnetization. Since the estab- 


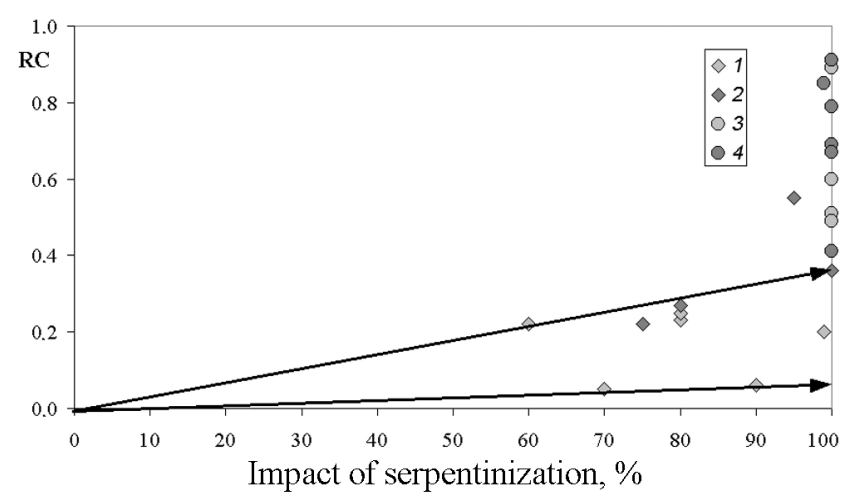

Figure 11. Comparative impact of serpentinization and medium-temperature metamorphic recrystallization on the relative content of the magnetic mineral (RC). 1 - the first stage of serpentinization, weakly (below 25\%) metamorphosed peridotite, 2 - same, strongly (above $25 \%$ ) metamorphosed peridotites, 3 - the second and the third stages of serpentinization, weakly (below 25\%) metamorphosed peridotites, 4 - same, strongly (above 25\%) metamorphosed peridotites. Arrows delimit the region typical of weakly metamorphosed peridotites of the 1st stage of serpentinization.

lished lower temperature limit for serpentinization of oceanic peridotites (and, accordingly, concomitant magnetite crystallization in them) is $100-150^{\circ} \mathrm{C}$ [Bonatti et al., 1984], the magnetic phase may crystallize in oceanic peridotites in a broad (on the order of $500^{\circ} \mathrm{C}$ ) temperature range. For the peridotites uplifted in the MAR axial zone and exposed, e.g., on rift valley slopes, this process takes some 5000 years (calculated using the same physical parameters as in [Bazylev and Silantiev, 2000]).

This time-span is incommensurate with the estimated duration of magnetite crystallization under serpentinization of ophiolitic peridotites, in excess of 2 million years $[N g u e n$ and Pechersky, 1989]. On the one hand, this is a yet another proof that serpentinization of peridotites in MORs and serpentinization of ophiolitic peridotites are entirely different processes, restricted to contrasting geodynamic settings and differing in mineralogically, petrologically, and geochemically [Bazylev, 2000]. On the other hand, the short timespan of magnetite crystallization in MOR-axis peridotites virtually precludes the likelihood of a geomagnetic polarity reversal during this process, and, accordingly, the presence in one sample of ferrimagnetic grains with opposite magnetization polarities [Pechersky and Didenko, 1995]. Note, however, that the cooling of peridotites that occur in the upper lithosphic mantle at MOR flanks and within ocean floor must proceed at an essentially slower rate, and, accordingly, the time-span in which these rocks acquire secondary magnetization may be considerably longer.

The strongest magnetization among the peridotites in point is exhibited by the metaperidotites formed near the relatively high- $\mathrm{T}\left(450-500^{\circ} \mathrm{C}\right)$ tectonic contact with gabbroids [Bazylev, 1997]. This suggests that medium-temperature metamorphism of oceanic peridotites may be a factor of influence on the formation of the linear magnetic anomalies

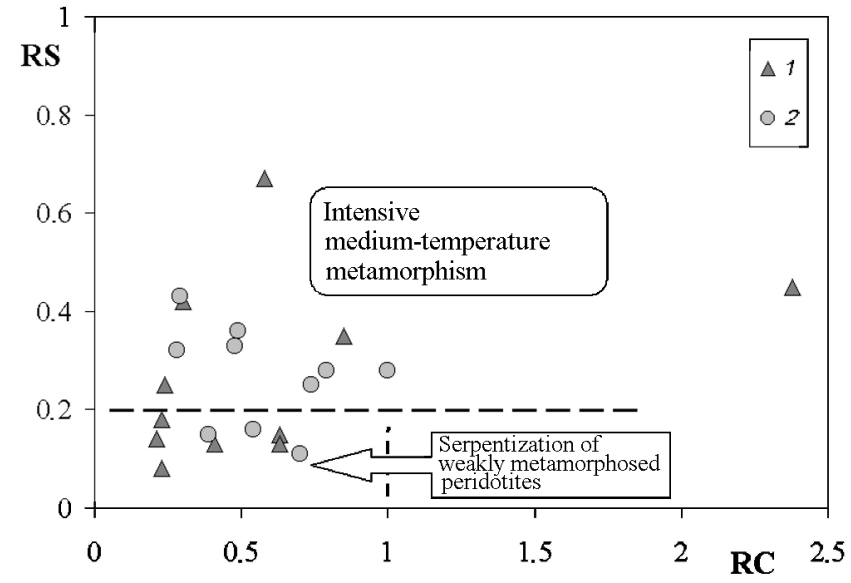

Figure 12. Relative content of the magnetic phase (RC) vs. mean relative grain size of the magnetic phase (RS) for MOR peridotites (average data from drillholes, dredges, or sampling localities, Table 3). 1 - data from this work, 2 - published data.

in the oceanic lithosphere [Bazylev et al., 2001]. Metaperidotites from the Hayes FZ, evidently, occurred at a nearly vertical fault plane, and induced in plan view a strong linear magnetic anomaly, marking the contact between peridotites and gabbroids. Such a mechanism for the formation of magnetic lineations in the oceanic lithosphere had not been considered [Nazarova and Gorodnitsky, 1986; Nguen and Pechersky, 1989].

\section{Conclusions}

1. Magnetization in MOR peridotites takes origin not only from their serpentinization, but also from the preceding medium-temperature recrystallization.

2 . The grain size of the magnetite that is formed at various stages of serpentinization of oceanic peridotite averages 3-4 $\mu \mathrm{m}$. Increased grain size of the magnetic mineral (on average, $20 \mu \mathrm{m}$ ) points to its crystallization during mediumtemperature metamorphism, already prior to serpentinization of the rocks.

3. The relatively large mean grain size of the ferrimagnetic in MOR peridotites further corroborates the broad development of medium-temperature metamorphic recrystallization of these rocks both within transform faults and on rift valley slopes.

4. For the lower boundary of the magnetic layer of oceanic lithosphere, one should adopt the depth of the $580^{\circ} \mathrm{C}$ isotherm, corresponding to the Curie point for magnetite. Accordingly, the thickness of this layer in MOR axial parts may reach $15 \mathrm{~km}$. 
Acknowledgments. We are deeply grateful to L. V. Dmitriev (Institute of Geochemistry and Analytical Chemistry, Russian Academy of Sciences) for providing us with peridotite samples recovered by the submersible Nautile, and to A. M. Gorodnitsky (Institute of Oceanology, Russian Academy of Sciences) for discussing our principal corollaries. This work was supported by the Russian Foundation for Basic Research (project nos. 01-05-64168, 99-05-64770) and by funding from the RF Ministry for Industry and Science.

\section{References}

Bazylev, B. A., Metamorphism of oceanic ultramafites (in Russian), Ph. D. Thesis, 213 pp., Institute of Geochemistry and Analytical Chemistry, Moscow, 1989.

Bazylev, B. A., Metamorphism of ultramafites from the Atlantis Fracture Zone, Atlantic Ocean: Evidence for water penetrating deep into oceanic lithosphere (in Russian), Dokl. Akad. Nauk SSSR, 323, 741-743, 1992.

Bazylev, B. A., Allochemical metamorphism of mantle peridotites from Hayes Fracture Zone, North Atlantic (in Russian), Petrologiya, 5, 362-379, 1997.

Bazylev, B. A., The development of an awaruite-bearing mineral assemblage in peridotites from the $15^{\circ} 20^{\prime}$ Fracture Zone, Atlantic Ocean: A manifestation of oceanic metamorphism (in Russian), Russ. J. Earth Sci., 2, (3), 2000.

Bazylev, B., K. Popov, and A. Gorodnitsky, Magnetic characteristics of peridotites and the nature of magnetic anomalies at the Mid-Atlantic Ridge, in Geology and Geophysics of Mid-Oceanic Ridges, 8, Proc. Working Conf. Memor. S.P. Mashchenkov, Russ. Division Intern. Proj. InterRidge (May 23-25, 2001), All-Russ. Research Inst. Oceanology, St. Petersburg, 2001.

Bazylev, B., and S. Silantiev, A geodynamic interpretation of subsolidus recrystallization of mantle spinel peridotites. 1. Midoceanic ridges (in Russian), Petrologiya, 8, (3), 227-240, 2000.

Bazylev, B. A., S. A. Silantiev, and N. N. Kononkova, Metamorphism of ultramafites in oceanic crust, in Magmatism and Tectonics of Oceans: Lithos Project, pp. 296-318, Nauka, Moscow, 1990.

Banerjee, S. K., The magnetic layer of oceanic crust-how thick is it?, Tectonophysics, 105, 15-27, 1984.

Bonatti, E., Y. R. Lawrence, and N. Morandi, Serpentinization of oceanic peridotites: temperature dependence of mineralogy and boron contents, Earth Planet. Sci. Letters, 70, 88-94, 1984.

Burakov, K. S., A. K. Gapeev, and A. N. Didenko, Magnetic properties of igneous rocks, in Structure of the Cape Verde Fracture Zone, Central Atlantic, pp. 149-161, Nauka, Moscow, 1989.

Dmitriev, L., B. Bazylev, M. Borisov, A. Bougault, S. Silantiev, and S. Sokolov, Generation of hydrogen and methane during serpentinization of oceanic mantle ultramafites and the origin of oil (in Russian), Russ. J. Earth Sci., 1, (6), 511-519, 1999.

Dunlop, D. J., and M. Prevot, Magnetic properties and opaque mineralogy of drilled submarine intrusive rocks, Geophys. J. Roy. Astr. Soc., 69, 763-802, 1982.

Gordin, V., E. Nazarova, and K. Popov, A generalized petromagnetic model for oceanic lithosphere (in Russian), Okeanologiya, 33, 139-143, 1993.

Gorodnitsky, A. M., and N. A. Shishkina, A generalized petro- magnetic model for oceanic lithosphere, in The Nature of Magnetic Anomalies and the Structure of Oceanic Crust, pp. 243252, All-Russian Research Institute of Fishery and Oceanography, 1996.

Gorognitsky, A. M., and K. V. Popov, New data about the nature of magnetic anomalies and earth crust structure in a zone of the Mid-Atlantic Ridge, InterRidge News, 9, (1), 23-26, 2000.

Kent, D. V., B. M. Honnorez, N. D. Opdyke, and P. J. Fox, Magnetic properties of dredged oceanic gabbros and the source of marine magnetic anomalies, Geophys. J. Roy. Astron. Soc., 55, 513-537, 1978.

Kimball, K. L., F. S. Spear, and H. J. B. Dick, High-temperature alteration of abyssal ultramafic rocks from the Islas Orcadas fracture zone, South Atlantic, Contrib. Mineral. Petrol., 94, 307-320, 1985.

Nazarova, E., and A. Gorodnitsky, Magnetic characteristics of deep layers of the oceanic crust and the structure of the anomalous magnetic field in the oceans (in Russian), Okeanologiya, 3, (26), 446-450, 1986.

Nguen, T. K. T., and D. Pechersky, Serpentinites: A likely source of magnetic lineations (in Russian), Izv. Akad. Nauk SSSR, Ser. Geol., 1, 61-67, 1989.

Pechersky, D. M., and A. N. Didenko, The Paleo-Asian Ocean: Petromagnetic and Paleomagnetic Data on Its Lithosphere, 298 pp., United Institute of Physics of the Earth, Moscow, 1995.

Pechersky, D., A. Didenko, A. Lykov, and L. Tikhonov, The petromagnetism of the oceanic lithosphere (in Russian), Fiz. Zemli, 12, 29-45, 1993.

Perchuk, L. L., and I. D. Ryabchikov, Phase Correspondence in Mineral Systems, 287 pp., Nedra, Moscow, 1976.

Popov, K. V., and V. P. Shcherbakov, Magnetic properties of serpentinites dredged from ocean floor, in A Petromagnetic Model of the Lithosphere, pp. 19-24, Naukova Dumka, Kiev, 1994.

Popov, K. V., and V. P. Shcherbakov, Petromagnetic characteristics of oceanic crustal rocks: Serpentinites, in The Nature of Magnetic Anomalies and the Structure of Oceanic Crust, pp. 82-132, All-Russian Research Institute of Fishery and Oceanography, Moscow, 1996.

Prinz, M., K. Keil, J. A. Green, A. M. Reid, E. Bonatti, and J. Honnorez, Ultramafic and mafic dredge samples from the equatorial Mid-Atlantic Ridge and fracture zones, J. Geophys. Res., 81, (23), 4087-4103, 1976.

Sack, R. O., and M. S. Ghiorso, Chromian spinels as petrogenetic indicators: thermodynamics and petrological applications, Am. Mineral., 76, 827-847, 1991.

Shcherbakov, V. P., B. E. Lamash, and V. V. Shcherbakova, The nature of magnetization of oceanic crustal rocks, in The Nature of Magnetic Anomalies and the Structure of Oceanic Crust, pp. 7-34, All-Russian Research Institute of Fishery and Oceanography, Moscow, 1996.

Silantiev, S., Metamorphism of modern oceanic basins (in Russian), Petrologiya, 3, 24-36, 1995.

Talwani, M., C. C. Windish, and M. G. Langseth, Reykjanes ridge crest: A detailed geophysical study, J. Geophys. Res., 76, 473$517,1971$.

Wicks F. J., and A. G. Plant, Electron-microprobe and $X$-ray microbeam studies of serpentine textures, Canad. Mineralogist, 17, 785-830, 1979.

Wicks, F. J., and E. J. W. Whittaker, Serpentine textures and serpentinization, Canad. Mineralogist, 15, 459-488, 1977. 